\title{
EXPLORING LOCAL RECIRCULATION OF PAPER WASTE THROUGH UPCYCLING AND ARTISTIC RECYCLING
}

\author{
Rohsig Lopez, Nicole Sofia; \\ Faucheu, Jenny \\ Mines Saint-Etienne, Univ Lyon, CNRS, UMR 5307 LGF, Centre SMS, F - 42023 Saint-Etienne \\ France
}

\begin{abstract}
Local recirculation of materials is a key aspect for a green transition, as it enables materials to be reused in new life cycles locally. In this article, we use the material "paper" as a case study to explore how this material recirculates at the local scales. This article aims at observing and evaluating upcycling scenarios as part of an expansion of local end-of-life possibilities compared to the current situation where paper end-of-life is reduced to a few recycling plants in France and abroad. This work relies on interviews and questionnaires that aim at understanding how paper is used and explored by artists to be recirculated in products. Indicators were tested to provide a methodology to compare different material circulation scenarios in terms of material use, environmental impact and value perception. Collaboration among multiple actors, artists, community centres, schools and industrial players is crucial for scaling up such recirculation loops.
\end{abstract}

Keywords: Circular economy, Sustainability, Ecodesign, Upcycling, Paper waste

\section{Contact:}

Rohsig Lopez, Nicole Sofia

Mines Saint-Etienne

Centre SMS

Brazil

nicole.rohsig@gmail.com 


\section{INTRODUCTION}

Historically, materials were extracted directly from the ground and were used by local communities. Its nature was geographically dependant (Ghyoot et al., 2018), but in today's globalised world, we can find different kinds of material independently of where we are. However, eco-localism criticises globalisation based on the following issues (Curtis, 2003): (i) it spreads Western consumer culture, increasing consumption and replacing local goods; (ii) it increases supply chain distances through continents and oceans, increasing gases emissions that contribute for climate change; (iii) it may motivate countries competing for foreign investment to reduce their environmental regulation following companies' demand for lower production costs. This way, local recirculation of materials is a key aspect for a green transition, as it enables materials to be reused in new life cycles locally, avoiding the problems aforementioned. Besides, one of the main aspects of circular economy is the recirculation of materials whose goal is to keep them in use at their highest level of utility at all times. Recirculating materials reduces the demand for virgin materials' inflow (Ellen MacArthur Foundation, 2015). It also cuts CO2 emissions and requires less energy than new production does (Material Economics, 2018).

In this article, we use the material "paper" as a case study to explore how this material recirculates at the local scales (here, the scale of the Auvergne-Rhone-Alpes region, in France). Among local paper recirculation scenarios, existing scenarios are considered such as upcycling artists and designers that manage to perform upcycling loops that add noticeable value into recycled paper. Fictive local paper recirculation that roots from existing local industries are also considered, such as the production of paper panels inspired by the production of wooden panels by a local industrial manufacturer. This article aims at observing and evaluating these upcycling scenarios as part of an expansion of local endof-life possibilities compared to the current situation where paper end-of-life is reduced to a few recycling plants in France and abroad.

In the first part, the context of the paper recycling industry today in France is depicted and so alternative scenarios are illustrated. This article represents a preliminary work related to a systemic description of "second-hand materials as a local source of materials". First, this work relies on interviews and questionnaires that aim at understanding how paper is used and explored by artists to be recirculated in products. Second, indicators were tested to provide a methodology to compare different material circulation scenarios in terms of material use, environmental impact and value perception.

\section{CONTEXT}

Today, paper recycling is perceived as an optimal solution for paper waste, considering the high percentage that can be recycled and this process's easiness (Material Economics, 2020). In the Auvergne-Rhone-Alpes region, 100,558 tons of paper waste were recovered in 2018 (Sindra, 2019a). In this region, there are fifty-six professional sorting centres (Sindra, 2019b). Most of the time, the waste is transported to recycling industries that are located outside Auvergne-Rhone-Alpes. We found only one recycling industry in the territory. Despite recycling's high efficiency, we must consider that today the French paper recycling sector faces a crisis (Chauvot, 2019; Jacqué, 2019). In France, 79\% of the paper and cardboard are recuperated to be sorted and then recycled (Chauvot, 2019). In 2019, 7 Mt of paper were collected, but only 5.3 Mt were consumed in France, leaving a surplus of 1.7 Mt (Chauvot, 2019; Delamarche, 2019). According to Pascal Geneviève, the cause of this unbalanced situation is the lack of paper recycling factories in French territory (Delamarche, 2019). Furthermore, China stopped importing waste for recycling in 2020 (Chauvot, 2019; Delamarche, 2019). This way, the resale price of paper and cardboard for recycling is no longer covering the costs of collecting, sorting, and disposal of ultimate waste (non-recyclable) (Delamarche, 2019). As a result, some existing recycling industries are closing their doors. For example, the UPM factory in Chapelle Darblay de Grand-Couronne, responsible for 25\% to $30 \%$ of the French recycling (Moiroud, Callier, 2020), announced in September 2019 that it would initiate a shutting down process in January 2020, if they did not find another buyer (Moiroud, Callier, 2020; Loubet, 2019). It could begin a chain reaction in which remaining industries would not be able to keep up with the amount of paper to be recycled. In this context, we can observe the current model's fragility relying on such a limited number of actors. Therefore, we should investigate new ways to employ paper waste at different value levels: from a unique art piece, passing through DIY solutions, and finally, mass-production alternatives. This process can diversify the industry and create new jobs. 


\section{METHODOLOGY}

In the current situation, paper circulation is based only on industrial recycling corresponding to a full paper transformation ending up to a low-value product. In a scenario of diversified local circulation of paper, several transformation scenarios should be combined to finally absorb the same amount of material but with different transformation levels that end up to a variety of product's values. For example, cardboard boxes reused as storage boxes without any transformation or DIY activities with paper pulp in local community centres are local paper circulation scenarios. Among these, some artists and designers have chosen paper as raw materials for their creative activities. These products are particular once they are transformed from waste (paper) to high added-value products.

To evaluate the feasibility, desirability, and limits of the work performed by paper upcycling artists and designers regarding material recirculation, this research was developed in three steps that will be thoroughly explained in the next sub-sections.

\subsection{Questionnaires: actors of artistic paper upcycling}

For artwork and artistic products using paper materials, we elaborated a questionnaire to understand the creation process, applied to designers and artists who work with recuperated paper. This questionnaire was divided into four sections: identification; raw material obtaining; transformation process; and the final value of the created object. Then, we analysed the collected data to identify the main characteristics of the process, their capacity for paper waste absorption, and the added value of their products.

\subsection{Indicators: evaluating scenarios for local recirculation of paper materials}

In order to compare the impacts, drawbacks and benefits of each material recirculation scenario, indicators were elaborated within three aspects: the quantitative material recirculation, the qualitative material recirculation process and the related social and professional interactions. As the objective of this study is to compare different scenarios, indicators were constructed as relative tools rather than absolute tools. First, the quantitative material recirculation is described with indicators that are related to the generic upcycling process, represented in Figure 1. A Waste (Waste IN) is identified as potential recirculated material: it becomes an Object that is going to be upcycled into a Product using (if needed) some external materials (Ext) and generating (or not) some Waste (Waste OUT).

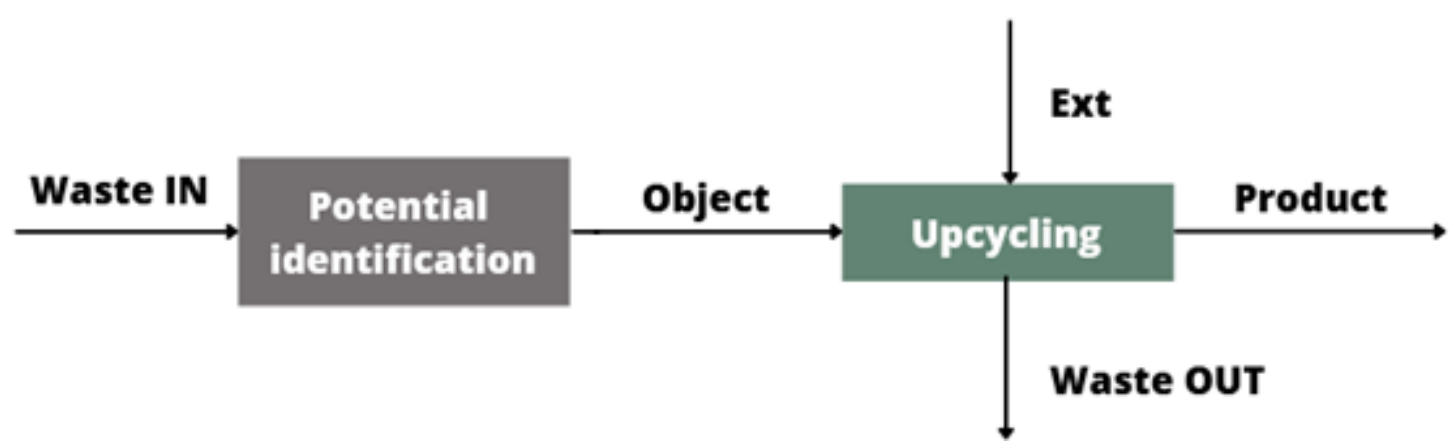

Figure 1. Upcycling process representation

Two indicators, inspired by classical environmental indicators (Bauraing et al., 2000) and indicators to assess performance in circular economy (Grimaud et al., 2018; Huysman et al., 2017; Saidani et al., 2017) are used to evaluate the ability of the upcycling scenario to make paper recirculate in terms of quantity of paper involved $\left(X_{\text {material absorption }}\right)$ and in terms of environmental performance $\left(X_{\text {green process }}\right)$. Through the material absorption indicator, we evaluate the productivity of the materials. This indicator is calculated through Equation 1, shown below:

$$
X_{\text {material absoption }}(\%)=100 *\left(m_{\text {object }} / m_{\text {product }}\right)
$$

Where:

$$
m_{\text {product }}+m_{\text {waste }}=m_{\text {object }}+m_{\text {external material }}
$$


The green process indicator considers the resource and energy consumption and the waste generation based on operational indicators of environmental performance (Bauraing et al., 2000). It is calculated through Equation 3, shown below:

$$
X_{\text {green process }}(\%)=100 *\left(N_{\text {green process }} / 90\right)
$$

Where $\mathrm{N}_{\text {green process }}$ is the green process score sum, considering the scores are presented in Table 1:

Table 1. Green process score

\begin{tabular}{|l|c|c|r|}
\hline RESOURCE CONSUMPTION & 10 & 5 & High \\
\hline Possible disassembly from waste to object & Low & Average & High \\
\hline $\begin{array}{l}\text { Deconstruction associated with the } \\
\text { upcycling process }\end{array}$ & Low & Average & High \\
\hline $\begin{array}{l}\text { Construction associated with the } \\
\text { upcycling process }\end{array}$ & Low & Average & High \\
\hline ENERGY CONSUMPTION & 10 & 5 & High \\
\hline Possible disassembly from waste to object & Low & Average & High \\
\hline $\begin{array}{l}\text { Deconstruction associated with the } \\
\text { upcycling process }\end{array}$ & Low & Average & High \\
\hline $\begin{array}{l}\text { Construction associated with the } \\
\text { upcycling process }\end{array}$ & Low & Average & High \\
\hline WASTE PRODUCTION & Low & Average & High \\
\hline Possible disassembly from waste to object & Low & Average & Average \\
\hline $\begin{array}{l}\text { Deconstruction associated with the } \\
\text { upcycling process }\end{array}$ & & & \\
\hline $\begin{array}{l}\text { Construction associated with the } \\
\text { upcycling process }\end{array}$ & & & \\
\hline
\end{tabular}

In order to qualify the perceived value of the upcycling strategy, an upcycling indicator is defined $\left(\mathrm{X}_{\text {upcycling }}\right)$ that agglomerates value characteristics: availability; preciousness; usability; and workability values of the transformation process. It is calculated using Equation 4:

$$
X_{\text {upcycling }}(\%)=100 *\left(N_{\text {upcycling }} / 105\right)
$$

Where $\mathrm{N}_{\text {upcycling }}$ is the upcycling's score sum, considering the scores are presented in Table 2:

\begin{tabular}{|c|c|c|c|c|}
\hline availability value & 0 & 5 & 10 & - \\
\hline Regularity of the stock/supply & $\begin{array}{l}\text { Single or } \\
\text { punctual }\end{array}$ & Seasonal & Permanent & - \\
\hline PRECIOUSNESS VALUE & 0 & 5 & 10 & - \\
\hline $\begin{array}{l}\text { Cultural, uniqueness and } \\
\text { aesthetics value }\end{array}$ & Low & Medium & High & - \\
\hline Financial value & Low & Medium & High & - \\
\hline USABILITY VALUE & 10 & 5 & 0 & - \\
\hline Sorting need & Low - loose & $\begin{array}{l}\text { Medium - rough } \\
\text { sorting }\end{array}$ & $\begin{array}{l}\text { High - } \\
\text { detailed } \\
\text { sorting }\end{array}$ & - \\
\hline Conditioning need & $\begin{array}{l}\text { Low - easily } \\
\text { stackable } \\
\text { without loss of } \\
\text { space }\end{array}$ & $\begin{array}{c}\text { Medium - } \\
\text { stackable with } \\
\text { loss of space }\end{array}$ & $\begin{array}{l}\text { High - hardly } \\
\text { stackable/ } \\
\text { great loss of } \\
\text { space }\end{array}$ & - \\
\hline $\begin{array}{l}\text { Need for characterisation of } \\
\text { the properties }\end{array}$ & $\begin{array}{l}\text { Low - little } \\
\text { information }\end{array}$ & $\begin{array}{l}\text { Medium - } \\
\text { partial } \\
\text { information }\end{array}$ & $\begin{array}{c}\text { High - } \\
\text { complete } \\
\text { information }\end{array}$ & - \\
\hline
\end{tabular}

Table 2. Upcycling score 


\begin{tabular}{|c|c|c|c|c|}
\hline WORKABILITY VALUE & 0 & 5 & 10 & 15 \\
\hline $\begin{array}{l}\text { Disassembly from waste to } \\
\text { object }\end{array}$ & $\begin{array}{c}\text { Complex } \\
\text { disassembly/ } \\
\text { manual }\end{array}$ & $\begin{array}{c}\text { Complex } \\
\text { disassembly but } \\
\text { easy to } \\
\text { automate }\end{array}$ & $\begin{array}{c}\text { Simple } \\
\text { disassembly } \\
\text { and easy to } \\
\text { automate }\end{array}$ & Nothing \\
\hline $\begin{array}{l}\text { Deconstruction associated with } \\
\text { the upcycling process }\end{array}$ & $\begin{array}{l}\text { Complex/ } \\
\text { Manual }\end{array}$ & $\begin{array}{l}\text { Complex but } \\
\text { automated }\end{array}$ & $\begin{array}{l}\text { Simple and } \\
\text { automated }\end{array}$ & Nothing \\
\hline $\begin{array}{l}\text { Construction associated with } \\
\text { the upcycling process }\end{array}$ & $\begin{array}{l}\text { Complex/ } \\
\text { Manual }\end{array}$ & $\begin{array}{l}\text { Complex but } \\
\text { automated }\end{array}$ & $\begin{array}{l}\text { Simple and } \\
\text { automated }\end{array}$ & Nothing \\
\hline
\end{tabular}

Even though the score given can lose its meaning by being considered within others in an additional manner, we consider that they can compensate each other in a similar logic to carbon footprint analysis (ISO 14064-1:2018). In the analysis of the results, we will further discuss which components contribute the most to the score result.

Finally, as the aim of this work is to explore the impact of local recirculation of materials at a local scale, an indicator related to the local economical interactions between professional activities is defined $\left(\mathrm{X}_{\text {local dynamic }}\right)$ that measures the number of local connections $\left(\mathrm{L}_{\text {local }}\right)$ such as clients or suppliers compared to the national $\left(\mathrm{L}_{\text {national }}\right)$ and international $\left(\mathrm{L}_{\text {international }}\right)$ ones, as shown in Equation 5:

$$
X_{\text {local dynamics }}(\%)=100 *\left[\frac{L_{\text {local }}}{L_{\text {local }}+L_{\text {national }}+L_{\text {international }}}\right]
$$

Then, we analyse the impact of upcycling in the territorial dynamic through the upcycling dynamic indicator $\left(\mathrm{X}_{\text {upcycling dynamic }}\right)$ that evaluates the number of potential connections after upcycling $\left(\mathrm{X}_{\text {up-loc dyn. }}\right)$ comparing the local dynamic indicators before $\left(\mathrm{X}_{0-\text { loc dyn }}\right)$. Its calculation is presented in Equation 6.

$$
X_{\text {upcycling dynamics }}(\%)=100 *\left(X_{u p-l o c d y n}-X_{0-l o c d y n}\right) / X_{0-l o c d y n}
$$

In this context, for each upcycling scenario, we listed the adequate actors of Auvergne-Rhone-Alpes in a $50 \mathrm{~km}$ radius. Depending on the scenario, these upcycling actors count art schools; artists that work with paper; sorting facilities; material libraries; fab labs; cultural centres and events; design studios; and a factory that could produce the paper OSB combined to stores that could sell this material.

To perform the evaluation through the indicators, the different scenarios studied are categorised following the classification of the material's level of degradation proposed by Menu et al. (2019), which is presented below:

- Repurpose: furniture, for instance, a coffee table made of old books.

- Refunction (1): collage made of magazines, maps, posters, gift paper, and books.

- Refunction (2): paper jewellery, for instance, a necklace made of paper magazines.

- Refunction (3): paper OSB, a board made of paper using the oriented strand board technique.

- $\quad$ Refunction (4): sculpture made of paper pulp.

- Industrial recycling: traditional paper recycling transforming paper waste into pulp and then into recycled paper.

\section{RESULTS AND DISCUSSION}

In this section, we present the results that were found in each step of the methodology. We discuss the results as we confront our findings with the information available in the literature.

\subsection{Questionnaires analysis: actors of artistic paper upcycling}

We received ten answers from seven artists and three designers who worked with paper as the main material: eight of them were from France, two from the United States. Half of them used only one kind of paper, while the other half used two or more kinds. Newspaper was the most used material, followed by book pages. To obtain the paper, three out of ten recover it for free, three through 
purchase, and one does both. Those who purchased their paper presented quite different costs when buying this material: $1 € / \mathrm{kg}, 5 € / \mathrm{kg}$, and $10 € / \mathrm{kg}$, this is related to the fact that different artworks require different kinds of paper with specific characteristics, therefore affecting material cost. Meanwhile, those who recover paper for free most commonly obtain it from their personal network and/or from organisations (large-scale retail, waste collection, and redistribution associations). According to Singh et al. (2019), one of the main challenges for upcyclers is the lack of materials with suitable quality in sufficient quantity, which could be solved through the creation of an infrastructure for database material provision and testing. This could be organised by NGOs or a consortium of actors across the upcycling value chain (Singh et al., 2019).

We can observe that artists and designers acquire a small paper volume: half of them get less than 10 $\mathrm{kg}$ per month, four out of ten between $10 \mathrm{~kg}$ and $30 \mathrm{~kg}$ per month, and only one of them between 30 $\mathrm{kg}$ and $50 \mathrm{~kg}$ per month. However, they do not use all the material they get: six out of ten use less than $10 \mathrm{~kg}$ per month, and four use between $10 \mathrm{~kg}$ and $30 \mathrm{~kg}$ per month. We calculate that the mass average of recuperated/purchased paper is $14.5 \mathrm{~kg}$ per month whereas the mass average of used paper is $11 \mathrm{~kg}$ per month. Not surprisingly, it appears that the artistic and design activities alone are not enough to absorb the paper waste of a region.

About the transformation process, we wanted to understand which operations were applied in the product fabrication. Six of the respondents said that they make their own paper pulp from which they create mouldings and sculptures. The other four said that they cut and assemble pieces of paper, creating collages and superpositions, sometimes, they draw and paint over that. Besides paper, all artists and designers used adhesives, glues, coatings, and paintings, and four professionals used metals. Regarding the product's end-of-life, seven of them said that their works were not recyclable in the traditional recycling sector. This raises an obstacle for circular economy scenarios, as these objects require special treatment when discarded, to be reintroduced in the paper industry. Thus, it would be important to adopt principles of design for disassembly, which demands that artists and upcyclers collaborate with all parties in the end-of-life (Bakker et al., 2010).

Analysing marketing aspects, half of them said that they produced on demand, the other half in small series. This reinforces the question of whether these activities can efficiently absorb the paper waste of a region given this market's size. In fact, the demand varies a lot: four out of ten said that they produce between one and ten objects per year, three of them produce between ten and twenty objects, and three of them produce twenty or more objects. Furthermore, we wanted to know if the public noticed that the raw material used in the object was paper. Thus, using a Likert scale, the artists and designers evaluated customer's awareness concerning the raw material, one (1) meaning that never realised it was paper, five (5) meaning they always realised it. It was interesting to note that there were two different patterns: the public that did not realise it was paper (usually when the products were sculptures), and the public that did notice it was paper (usually when the products were collages).

\subsection{Indicators: evaluating scenarios for local recirculation of paper materials}

Regarding environmental indicators, we can see the results below, in Table 3. For material absorption $\left(\mathrm{X}_{\text {material absoption }}\right)$, we estimated the incoming paper's mass and the final product's mass. On one hand, we note that the paper OSB (board) and the industrial recycling have the highest absorption rates because basically, all the mass of the final product comes from the incoming object (paper), and we can dismiss the mass of the external objects (such as adhesives). The paper sculpture has also a high absorption rate because it has less mass from external materials: composed of water and glue, and sometimes structure metals. On the other hand, in paper jewellery, there are other elements, e.g., the cord and ornaments (such as stones) that have considerable mass when compared to the paper input. Considering the green process indicator $\left(\mathrm{X}_{\text {green process }}\right)$ : the book coffee table; collage; and the paper jewellery had low levels of resource consumption, energy consumption, and waste production.

Meanwhile, paper sculptures had a medium green process result because the construction and the destruction associated with the upcycling process had a medium level, consuming more resources than the other processes. The lower results for the green process indicators were the ones regarding the paper OSB and the industrial recycling, once they consume more resources and energy because they are industrial processes. 
Table 3: Environmental indicators' results

\begin{tabular}{|l|c|c|c|c|c|r|}
\hline $\begin{array}{l}\text { Environment } \\
\text { al indicator }\end{array}$ & Repurpose & $\begin{array}{c}\text { Refunction } \\
(1)\end{array}$ & $\begin{array}{c}\text { Refunction } \\
(2)\end{array}$ & $\begin{array}{c}\text { Refunction } \\
(3)\end{array}$ & $\begin{array}{c}\text { Refunction } \\
(4)\end{array}$ & $\begin{array}{r}\text { Industrial } \\
\text { recycling }\end{array}$ \\
\cline { 2 - 6 } & $\begin{array}{c}\text { Book } \\
\text { coffee table }\end{array}$ & Collage & $\begin{array}{c}\text { Paper } \\
\text { jewellery }\end{array}$ & Paper OSB & $\begin{array}{c}\text { Paper } \\
\text { sculpture }\end{array}$ & 100 \\
\hline $\begin{array}{c}\mathrm{X}_{\text {material }}(\%) \\
\text { absoption }\end{array}$ & 75 & 67 & 50 & 100 & 83 & 39 \\
\hline $\begin{array}{c}\mathrm{X}_{\text {green }}(\%) \\
\text { process }\end{array}$ & 100 & 100 & 100 & 78 & 89 & \\
\hline
\end{tabular}

Regarding the upcycling indicator $\left(\mathrm{X}_{\text {upcycling }}\right)$, we considered scenarios of local sourcing. The results of the upcycling indicators are shown in Table 4. Paper OSB presented the best results. Even though it has a low preciousness value, the need for sorting the material and conditioning for this product is lower than for the other cases, and its process can be automated. This way, it has higher usability and workability values. The same reasoning applies to industrial recycling. However, its preciousness value is lower than the one for paper OSB. Among the artistic products, collage presented the best results, once it keeps the cultural value of the magazine and it has a high artistic and financial value. Furthermore, it is easy to store and disassemble the material for future uses in upcycling processes. In comparison, paper sculptures also have a high artistic and financial value, but they are more difficult to store and disassemble. This way, this indicator evaluated created value in the upcycling process, whose principle is to maintain or to increase the item's original value (Bhatt et al., 2018).

Table 4: Upcycling indicators' results

\begin{tabular}{|l|c|c|c|c|r|r|}
\hline Value/Product & Repurpose & $\begin{array}{c}\text { Refunction } \\
(1)\end{array}$ & $\begin{array}{c}\text { Refunction } \\
(2)\end{array}$ & $\begin{array}{c}\text { Refunction } \\
(3)\end{array}$ & $\begin{array}{c}\text { Refunction } \\
(4)\end{array}$ & $\begin{array}{r}\text { Industrial } \\
\text { recycling }\end{array}$ \\
\cline { 2 - 6 } & $\begin{array}{c}\text { Book } \\
\text { coffee } \\
\text { table }\end{array}$ & Collage & $\begin{array}{c}\text { Paper } \\
\text { jewellery }\end{array}$ & Paper OSB & $\begin{array}{c}\text { Paper } \\
\text { sculpture }\end{array}$ & 10 \\
\hline $\begin{array}{l}\text { AVAILABILITY } \\
\text { VALUE }\end{array}$ & 5 & 10 & 10 & 10 & 10 & 0 \\
\hline $\begin{array}{l}\text { PRECIOUSNESS } \\
\text { VALUE }\end{array}$ & 10 & 20 & 0 & 5 & 20 & 30 \\
\hline $\begin{array}{l}\text { USABILITY } \\
\text { VALUE }\end{array}$ & 5 & 25 & 30 & 30 & 10 & 30 \\
\hline $\begin{array}{l}\text { WORKABILITY } \\
\text { VALUE }\end{array}$ & 30 & 10 & 0 & 30 & 15 & 70 \\
\hline TOTAL & 50 & 65 & 40 & 75 & 55 & 67 \\
\hline $\begin{array}{l}\text { UPCYCLING } \\
\text { SCORE (\%) }\end{array}$ & 48 & 62 & 38 & 71 & 52 & \\
\hline
\end{tabular}

Finally, for the territorial dynamic indicator, we analysed the scenarios taking the industrial recycling as a reference scenario, considering a 50km radius area within the Auvergne-Rhone-Alpes region. In this industrial recycling reference scenario, we listed one recycling factory and thirteen sorting facilities. Considering that in France, 65\% of the paper waste is used in national territory, 30\% is exported for European Union countries, and 5\% for other countries (Copacel, 2019), we calculated that there were four local connections, five national connections, and four international connections. Therefore, the local dynamic indicator for the reference scenario $\left(\mathrm{X}_{0-\text { loc dyn }}\right)$ is $30.8 \%$. For the upcycling scenarios, in addition to recycling factories and sorting facilities, we listed actors that could absorb paper in an upcycling scenario: art schools; artists that work with paper; sorting facilities; material libraries; fab labs; cultural centres and events; design studios; and a factory that could produce the paper OSB combined to stores that could sell this material. We ended up with seventy connections, all of them local. Thus, the local dynamic indicator after upcycling $\left(\mathrm{X}_{\text {up-loc dyn }}\right)$ is $100 \%$. This way the final local dynamic indicator $\left(X_{\text {upcycling dynamic }}\right)$ that compares upcycling scenarios to 
reference scenario is $225 \%$, meaning that the local dynamic more than doubled with upcycling. Scaling up upcycling could improve the circularity of resources, reduce dependency on imports, increase material and energy efficiency and create new jobs (Singh et al., 2019).

\section{CONCLUSION}

In this article, "paper" was studied as a potential "raw material" that can circulate and recirculate at local scales, maintaining value over circulation loops. Local paper upcycling and handmade recycling generate a lot of new business connections with more players involved in the local recirculation of materials, for instance, art schools; artists that work with paper; sorting facilities; material libraries; fab labs; cultural centres and events; design studios; and a factory that could produce the paper OSB combined to stores that could sell this material. Collaboration among multiple actors is crucial for scaling up such recirculation loops (Singh et al., 2019). Furthermore, artists' and designers' activities alone are not enough to absorb all the paper waste of the region. Industrial players could be added to the network developing innovative products that absorb higher volumes of material waste, for instance, cardboards for construction using wooden OSB's technique. There are already some solutions in the market that follow this idea, e.g., NewspaperWood $\odot$.

The hypothesis is that through complementary upcycling and handmade recycling strategies that rely on local strengths, a wide range of options to make paper circulate can be developed. Some processes are automated, industrialised, or should remain handcrafted. Such local development might favour local commercial interactions. This research contributes to highlighting the importance of the work that is performed by local actors regarding environmental and business impact in the region. However, such material recirculation scenarios face challenges such as materials' unavailability (especially with quality and quantity required), difficulties in marketing the products, and lack of resources (financial issues and problems with working structure) (Singh et al., 2019). Possible solutions are creating a database material provision and testing with the collaboration of suppliers across the value chain, giving financial support for upcycling business through government policies, and bringing awareness to the population about its importance (Singh et al., 2019) because customers usually have a negative perception of upcycled products (Singh et al., 2019; Bridgens et al., 2018). Furthermore, the regional factor is also important. Upcycling could reduce the dependency on imports and help to create jobs in local manufacturing practices (Singh et al., 2019).

\section{REFERENCES}

Bakker, C.A., Wever, R., Teoh, Ch. and De Clercq, S. (2010), "Designing cradle-to-cradle products: a reality check", International Journal of Sustainable Engineering, Vol. 3 No. 1, pp. 2-8. https://doi.org/10.1080/19397030903395166

Bauraing, E., Nicolas, J., von Frenckell, M. (2000), Les Indicateurs de Performances Environnementales, Fondation Universitaire Luxembourgeoise, Arlon.

Bhatt, D., Silverman, J. and Dickson, M.A. (2018), "Consumer interest in upcycling techniques and purchasing upcycled clothing as an approach to reducing textile waste", International Journal of Fashion Design, Technology and Education, Vol. 12 No. 1, pp. 118-128. https://doi.org/10.1080/17543266.2018.1534001

Bridgens, B., Powell, M., Farmer, G., Walsh, C., Reed, E., Royapoor, M., Gosling, P., et al. (2018), "Creative upcycling: Reconnecting people, materials and place through making”, Journal of Cleaner Production, Vol. 189, pp. 145-154. https://doi.org/10.1016/j.jclepro.2018.03.317

Chauvot, M. (2019), Crise Ouverte Dans Le Recyclage Du Papier Carton. [online] Les Echos. Available at: https://www.lesechos.fr/industrie-services/energie-environnement/crise-ouverte-dans-le-recyclage-dupapier-carton-1144116 (accessed 23 May 2020).

Copacel (2019), Rapport Statistique 2018 de l'Industrie Papetière Française, Union Française des Industries des Cartons, Papiers et Celluloses, Paris.

Curtis, F. (2003), "Eco-localism and Sustainability”, Ecological Economics, Vol. 46, No. 1, pp. 83-102. https://doi.org/10.1016/S0921-8009(03)00102-2

Delamarche, M. (2019), Saturés, Les Centres De Tri Pourraient Refuser Les papiers-cartons Des Collectivités L'Usine Matières Premières. [online] L'Usine Nouvelle. Available at: https://www.usinenouvelle.com/article/satures-les-centres-de-tri-pourraient-refuser-les-papiers-cartons-descollectivites.N867910 (accessed 31 May 2020).

Ellen MacArthur Foundation (2015), Towards a Circular Economy: Business Rationale for an Accelerated Transition, Ellen MacArthur Foundation. 
Geissdoerfer, M., Savaget, P., Bocken, N.M.P. and Hultink, E.J. (2017), “The Circular Economy - a New Sustainability paradigm?”, Journal of Cleaner Production, Vol. 143, pp. 757-768. https://doi.org/10.1016/j.jclepro.2016.12.048

Ghyoot, M., Devlieger, L., Billet, L. and Warnier, A. (2018), Déconstruction Et Réemploi: Comment Faire Circuler Les Éléments De Construction, PPUR, Laussane.

Grimaud, G., Laratte, B. and Perry, N. (2017). "How to Develop Indicators to Assess the Sustainability of Recycling Processes?", 10th International Symposium on Environmentally Conscious Design and Inverse Manufacturing, Tainan, Taiwan, pp. 6.

Huysman, S., De Schaepmeester, J., Regaert, K., Dewulf, J. and De Meester, J. (2017), "Performance indicators for a circular economy: A case study on post-industrial plastic waste", Resources, Conservation and Recycling. Vol 120, pp. 46-54. https://doi.org/10.1016/j.resconrec.2017.01.013

ISO 14064-1:2018 Greenhouse gases — Part 1: Specification with guidance at the organization level for quantification and reporting of greenhouse gas emissions and removals.

Jacqué, P. (2019), La Crise Sans Fin Des Papetiers En France. [online] Le Monde.Fr. Available at: https://www.lemonde.fr/economie/article/2019/09/11/la-crise-sans-fin-des-papetiers-enfrance_5509073_3234.html (accessed 23 May 2020).

Loubet, M. (2019), Coup De Massue Pour 236 salariés, Près De Rouen : l'usine De Papier UPM Annonce Sa Mise En Vente. [online] Actu.Fr. Available at: https://actu.fr/normandie/grand-couronne_76319/coupmassue-236-salaries-pres-rouen-lusine-papier-upm-annonce-mise-vente_27120643.html (accessed 23 November 2020).

Material Economics (2018), The Circular Economy - a Powerful Force for Climate Mitigation, Material Economics, Stockholm.

Material Economics (2020), A Net-Zero Transition for EU Industry - What Does It Mean for the Pulp \& Paper Industry?, Material Economics, Stockholm.

Menu, B., Jenny, F., Valérie, L. and Jean-François, B. (2019), "From Product to Dust: Looking at the Ways to Regenerate Value in Product Life Cycle", Design Society: International Conference on Engineering Design, Delft, The Netherlands, 5-8 August 2019, Vol. 1 No. 1, pp. 3321-3330. https://doi.org/10.1017/dsi.2019.339

Moiroud, M. and Cailler, S. (2020), Grand-Couronne : Une Commission Sur l'avenir Incertain De l'usine De Papier UPM Chapelle Darblay. [online] France 3 Normandie. Available at: https://france3regions.francetvinfo.fr/normandie/seine-maritime/rouen/grand-couronne-commission-avenir-incertainusine-papier-upm-chapelle-darblay-1771349.html (accessed 23 May 2020).

Saidani, M., Bernard, Y., Leroy, Y. and Cluzel, F. (2017). "How to Assess Product Performance in the Circular Economy? Proposed Requirements for the Design of a Circularity Measurement Framework", Recycling, Vol. 2, No. 1, 6. https://doi.org/10.3390/recycling2010006

Sindra (2019a), Collecte des déchets ménagers et assimilés en Auvergne-Rhône-Alpes en 2018. [online] Observatoire de déchets en Auvergne-Rhône-Alpes. Available at: https://www.sindra.org/dechets-auvergnerhone-alpes/collecte (accessed 15 March 2021).

Sindra (2019b), Les déchèteries professionnelles en Auvergne-Rhône-Alpes. [online] Observatoire de déchets en Auvergne-Rhône-Alpes. Available at: https://www.sindra.org/dechets-auvergne-rhone-alpes/collecte (accessed 15 March 2021)

Singh, J., Sung, K., Cooper, T., West, K. and Mont, O. (2019), “Challenges and Opportunities for Scaling up Upcycling Businesses - the Case of Textile and Wood Upcycling Businesses in the UK", Resources, Conservation and Recycling, Vol. 150, p. 104439. 


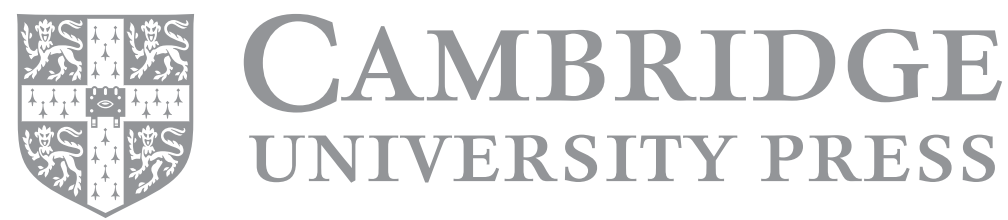

